\title{
PERSONAL FABLE, PERCEIVED PARENTAL MONITORING, DAN PERILAKU BERISIKO PADA REMAJA DI BANDUNG
}

\author{
Shara Rhamdayanti, Tina Hayati Dahlan, Gemala Nurendah \\ Departemen Psikologi, Universitas Pendidikan Indonesia \\ Jalan Doktor Setiabudhi No. 229, Bandung \\ E-mail: srhamdayanti@gmail.com
}

\begin{abstract}
ABSTRAK
Tujuan dari penelitian ini adalah untuk mengidentifikasi kontribusi personal fable dan perceived parental monitoring secara simultan terhadap perilaku berisiko pada remaja di Bandung. Penelitian ini menggunakan metode kuantitatif yang dianalisis dengan menggunakan teknik analisis regresi linier berganda. Instrumen yang digunakan dalam penelitian ini adalah adaptasi dari New Personal Fable Scale untuk menjaring data personal fable, Parental Monitoring Questionnaire untuk menjaring data perceived parental monitoring, dan Risk-Taking Scales untuk menjaring data perilaku berisiko. Penelitian ini melibatkan 395 remaja berusia 13 - 18 tahun di Bandung dengan status sebagai siswa. Hasil penelitian menunjukkan bahwa personal fable dan perceived parental monitoring secara simultan tidak berkontribusi terhadap perilaku berisiko pada remaja. Setelah dilakukan pengujian secara parsial, ditemukan bahwa personal fable tidak berkontribusi terhadap perilaku berisiko, sedangkan perceived parental monitoring berkontribusi terhadap perilaku berisiko.
\end{abstract}

Kata kunci: personal fable; perceived parental monitoring; perilaku berisiko; remaja; Bandung

\section{PERSONAL FABLE, PERCEIVED PARENTAL MONITORING, AND ADOLESCENT RISK BEHAVIOR IN BANDUNG}

\begin{abstract}
The purpose of this study is to identify the contribution of personal fable and perceived parental monitoring simultaneously to adolescent risk behavior in Bandung. This research uses quantitative methods that are analyzed using multiple linear regression analysis technique. The instrument used in this study was an adaptation of the New Personal Fable Scale to measure personal fable data, Parental Monitoring Questionnaire to measure perceived parental monitoring data and Risk-Taking Scales to measure risk behavior data. This study involved 395 adolescent students aged $13-18$ years in Bandung. The results show that simultaneous personal fable and perceived parental monitoring does not contribute to risk behavior in adolescents. After partial testing, it was found that personal fable does not contribute to risk behavior, whereas perceived parental monitoring contributes to risk behavior.
\end{abstract}

Keyword: personal fable; perceived parental monitoring; risk behavior; adolescent; Bandung

\section{PENDAHULUAN}

Remaja merupakan individu yang sedang gemar dan berani melakukan hal-hal baru yang menantang. Hal tersebut merupakan perilaku yang cenderung memiliki dampak negatif di kemudian hari misalnya melakukan hubungan seksual pranikah, penggunaan obat-obatan terlarang, mengonsumsi alkohol dan merokok (Sulistiyowati \& Senewe, 2010). Menurut data Badan Kependudukan dan Keluarga Berencana Nasional, Indonesia mengalami peningkatan sekitar $15 \%$ pada setiap tahunnya terkait hubungan seksual pranikah yang dilakukan oleh remaja (Ungsianik \& Yuliati, 2017). Hal tersebut didukung oleh data Survei Demografi dan Kesehatan Indonesia (2018) yang memaparkan bahwa Survei Litbang Kesehatan yang bekerja sama dengan UNESCO menunjukkan sebanyak 56\% remaja di Indonesia melakukan hubungan seksual sebelum menikah. Provinsi di Indonesia yaitu Jawa Barat merupakan provinsi yang terlibat dalam perilaku berisiko penggunaan obatobatan terlarang. Diberitakan oleh detik.com (2013), Badan Narkotika Nasional Provinsi (BNNP) Jawa Barat melaporkan bahwa pada tahun 2011, pengguna 
obat-obatan terlarang mencapai 960.000 orang dengan rentang usia $10-60$ tahun. Data tersebut menempatkan Jawa Barat di peringkat kelima sebagai provinsi dengan penyalahgunaan obat-obatan terlarang dan berdasar data tersebut, Bandung menjadi penyumbang paling besar.

Selain menjadi penyumbang terbesar untuk penyalahgunaan obat-obatan terlarang, perilaku berisiko lain, yaitu konsumsi alkohol untuk wilayah Bandung pun cenderung menjadi perhatian. Detik.com (2018) memberitakan bahwa berdasarkan data dari Survei Demografi dan Kesehatan Indonesia, terhitung pada tahun 2017, konsumsi alkohol pada remaja usia sekolah mengalami peningkatan. Data tersebut memaparkan bahwa pada usia 15 - 19 tahun tercatat $70 \%$ laki-laki dan $58 \%$ perempuan menyatakan diri pernah meminum minuman beralkohol. Hal tersebut berbeda pada individu dengan rentang usia $20-24$ tahun yang hanya $18 \%$ untuk laki-laki dan $8 \%$ untuk perempuan.

Selain itu, diberitakan oleh republika.co.id (2017), Santi Indra Astuti sebagai pegiat smoke free Bandung (SFB) memaparkan bahwa terdapat remaja yang sudah menjadi perokok aktif. Alasan remaja merokok pun beragam, misalnya karena sudah menjadi gaya hidup dan untuk dianggap hebat oleh orang lain.

Perilaku berisiko pada remaja tersebut dapat dipengaruhi oleh personal fable. Lapsley, FitzGerald, Rice, \& Jackson (1989) menjelaskan bahwa personal fable merupakan keyakinan remaja bahwa dirinya spesial atau unik, berkuasa, dan juga kebal. Personal fable merupakan komponen penting yang dapat menjelaskan perilaku berisiko pada remaja (Saudi, Hartini, \& Bahar, 2018). Landicho, Cabanig, Cortes, \& Villamor (2014) pun menunjukkan bahwa personal fable dapat memprediksi perilaku berisiko pada remaja. Menurut Leather (2009), personal fable memengaruhi perilaku berisiko pada remaja ditandai dengan munculnya rasa kebal akan perilaku berisiko, keyakinan akan memiliki kemampuan yang lebih dibanding orang lain, dan keyakinan bahwa mereka adalah pribadi yang unik dan tidak ada yang menyamai juga memahaminya. Penelitian yang dilakukan oleh Landicho dkk. (2014) menunjukkan bahwa invulnerability sangat terkait dengan perilaku berisiko. Penelitian oleh Ritcher (2010) juga menunjukkan korelasi antara personal fable dengan perilaku berisiko, yang mana terlibatnya remaja dalam perilaku berisiko dikarenakan remaja tersebut merasa yakin dan percaya diri akan keputusannya dan tidak memikirkan konsekuensi dari perilakunya tersebut.

Selain personal fable, selama tiga dekade terakhir, lebih dari 350 penelitian dilakukan terkait perilaku berisiko pada remaja yang dihubungkan dengan orang tua, khususnya praktik pengasuhan (Stattin, Kerr, \& Tilton-Weaver, 2010). Laird, Marrero, \& Sentse (2010) sebelumnya melakukan penelitian tentang perceived parental monitoring karena hal tersebut merupakan komponen penting untuk remaja yang sudah mulai jauh dari pengawasan orang tua. Peran orang tua dianggap dapat memengaruhi keterlibatan remaja dalam perilaku berisiko.
Perceived parental monitoring juga dapat memengaruhi perilaku berisiko pada individu dengan usia, jenis kelamin, dan pengalaman seksual yang berbeda (Dittus dkk., 2015). Perceived parental monitoring merupakan persepsi remaja terhadap aturan, pemantauan, dan informasi yang dimiliki orang tua tentang dirinya, baik yang berasal dari remaja tersebut maupun dari orang lain (Stattin dkk., 2010).

Suwarni, Ismail, Prabandari, \& Adiyanti (2015) dalam penelitiannya mengemukakan bahwa perceived parental monitoring dapat membantu remaja untuk mengurangi perilaku berisiko. Tingginya perceived parental monitoring berkorelasi dengan rendahnya perilaku berisiko yang dilakukan oleh remaja, misalnya konsumsi alkohol dengan hubungan seksual pranikah (Strunin dkk., 2013; Walsh, Harel-Fisch, \& FogelGrinvald, 2010).

Hasil penelitian dari Villarreal \& Nelson (2018) menunjukkan bahwa remaja yang memersepsikan orang tuanya melakukan pemantauan yang aktif cenderung terlibat dalam domain perilaku berisiko yang lebih sedikit. Adapun hal-hal yang membedakan apakah perceived parental monitoring tinggi atau rendah dapat dilihat dari empat hal: persepsi remaja terhadap pengetahuan orang tuanya, aturan yang diberikan orang tuanya, informasi yang dimiliki oleh orang tuanya, dan pengungkapan informasi kepada orang tuanya (Stattin dkk., 2010).

Penjelasan di atas menunjukkan bahwa baik personal fable dan perceived parental monitoring secara signifikan memengaruhi perilaku berisiko, tetapi berperan secara terpisah. Hal tersebut menjadi dasar peneliti untuk melakukan penelitian yang menggabungkan keduanya untuk melihat sejauh mana tingkat pengaruh dan variasi dua hal tersebut terhadap perilaku berisiko pada remaja di Bandung.

\section{METODE}

Penelitian ini menggunakan pendekatan kuantitatif korelasional dengan tujuan untuk mengukur derajat pengaruh personal fable $\left(\mathrm{X}_{1}\right)$ dan perceived parental monitoring $\left(\mathrm{X}_{2}\right)$ terhadap perilaku berisiko $(\mathrm{Y})$ pada remaja di Bandung. Populasi yang diteliti ialah remaja laki-laki dan perempuan yang tinggal di Kota Bandung. Menurut hasil survei yang dilakukan oleh Badan Pusat Statistik (BPS) pada tahun 2014, persentase remaja di Indonesia sebesar 24,53\%. Jawa Barat merupakan provinsi urutan pertama dengan jumlah remaja terbanyak yaitu sekitar 11,57 juta menurut hasil survei BPS. Data yang tersedia pada laman BPS pun menyebutkan bahwa persentase remaja di perkotaan lebih besar daripada di pedesaan. Hal ini didukung dengan hasil survei Badan Kependudukan dan Keluarga Berencana Nasional pada tahun 2017 yang menyatakan bahwa Kota Bandung selaku ibukota provinsi Jawa Barat memiliki nilai perilaku berisiko yang cukup tinggi.

BPS juga menyebutkan bahwa di Bandung, sebesar $70,31 \%$ remaja masih bersekolah, sementara $28,93 \%$ lainnya tidak bersekolah, sehingga penelitian ini 
menjadikan 395 siswa sekolah menengah dengan rentang usia 13 - 18 tahun sebagai sampel penelitian.

Pengambilan sampel dalam penelitian ini menggunakan teknik probability dan multistage cluster sampling. Teknik multistage cluster sampling dalam prosesnya dilakukan melalui beberapa tahapan (Creswell, 2012). Tahap yang dilakukan dalam penelitian ini ialah mengklasifikasikan dan mencatat jumlah SMP dan SMA berdasar cluster, menentukan jumlah SMP dan SMA yang terlibat dalam setiap cluster kemudian memilih SMP dan SMA, dan menghitung jumlah siswa SMP dan SMA di sekolah yang dipilih tersebut.

Penelitian ini menggunakan instrumen New Personal Fable Scale (NPFS) yang mengukur personal fable yang dibuat oleh Lapsley dkk. (1989). Instrumen NPFS terdiri 46 butir pernyataan dilengkapi dengan lima skala jawaban yaitu 1 (Sangat Tidak Setuju), 2 (Tidak Setuju), 3 (Netral), 4 (Setuju) dan 5 (Sangat Setuju). Instrumen NPFS ini selanjutnya diadaptasi dan diuji coba kepada remaja sehingga diketahui bahwa terdapat 2 butir pernyataan yang perlu dieliminasi yaitu butir pernyataan nomor 10 dan 14, karena tidak layak. Instrumen NPFS yang telah diadaptasi dan diuji coba memiliki reliabilitas 0,82 dengan keterangan bagus sekali.

Selain itu, penelitian ini pun menggunakan instrumen yang dibuat oleh Stattin dkk. (2010) yaitu The Parental Monitoring Questionnaire (PMQ) untuk mengukur perceived parental monitoring. Instrumen PMQ terdiri dari 22 butir pernyataan dengan rentang skala 1 (Tidak Pernah), 2 (Jarang), 3 (Kadang-kadang), 4 (Sering) dan 5 (Selalu). Instrumen ini diadaptasi dan diuji coba kepada remaja sehingga diketahui bahwa terdapat 3 butir pernyataan yang dieliminasi yaitu butir pernyataan nomor 13 , 10, dan 6, Instrumen PMQ memiliki reliabilitas sebesar 0,72 dan 0,73 dengan keterangan baik untuk dimensi parental knowledge dan parental solicitation, kemudian sebesar 0,86 dengan keterangan sangat baik untuk dimensi parental control, dan sebesar 0,69 dengan keterangan cukup baik untuk dimensi youth disclosure. Instrumen ini hanya diberikan kepada remaja untuk melihat persepsinya terhadap pemantauan yang dilakukan oleh orang tua karena remaja sebagai sumber utama dari informasi yang didapat oleh orang tua dinilai lebih akurat dalam mengutarakan apa yang sebenarnya terjadi (Stattin \& Kerr, 2000).

Untuk mengukur perilaku berisiko, penelitian ini menggunakan instrumen yang dibuat oleh Hansen \& Breivik (2001), yaitu Risk-Taking Scales yang sengaja dibuat untuk penelitiannya. Instrumen perilaku berisiko terdiri dari 18 butir pernyataan dengan skala "Tidak Pernah," "Pernah," dan "Sering." Instrumen RiskTaking Scales yang telah diadaptasi dan diuji coba kepada remaja menunjukkan hasil bahwa terdapat 3 butir pernyataan yang perlu dieliminasi yaitu 15, 16, dan 18, Reliabilitas dari instrumen ini sebesar 0,72 dengan keterangan baik untuk digunakan.

Pengambilan data dilakukan dengan menggunakan kuesioner yang terbagi menjadi empat bagian, yaitu identitas diri, variabel personal fable, perceived parental monitoring, dan perilaku berisiko. Cara yang digunakan untuk penyebaran data ialah dengan offline dan online. Cara offline dilakukan dengan mendatangi lingkungan sekolah yang sebelumnya dipilih untuk menjadi sampel penelitian. Selain itu, peneliti juga meminta bantuan dengan menitipkan lembar kuesioner pada keluarga juga kerabat peneliti yang memiliki kenalan yang sedang bersekolah atau menjadi pengajar di sekolah yang telah ditentukan. Penyebaran data dengan cara online dilakukan dengan menghubungi siswa yang beberapa di antaranya menjabat sebagai ketua OSIS di sekolah yang telah ditentukan melalui Instagram. Pengisian data secara online dilakukan melalui google form dengan tautan bit.ly/SkripsiShara.

Pengambilan data dalam penelitian ini dilakukan selama 20 hari terhitung dari tanggal 5 - 25 September 2019. Hasilnya, terdapat 296 data yang terkumpul dengan cara offline, sedangkan 99 data lainnya terkumpul dengan cara online. Pengambilan data dalam penelitian ini dapat dikatakan terarah meskipun dilakukan dengan cara dititipkan atau bahkan secara online melalui google form karena tetap tertuju pada siswa yang bersekolah di sekolah yang sudah ditentukan sebelumnya.

Teknik analisis data dalam penelitian ini ialah teknik korelasi dengan menggunakan analisis regresi linier berganda. Sebelum dilakukan analisis regresi linier berganda, data mentah berupa data ordinal ditransformasikan ke dalam bentuk rasio menggunakan Rasch Model pada Winstep. Setelah ditransformasi, data diolah menggunakan SPSS dengan analisis regresi linier berganda untuk mengetahui pengaruh personal fable $\left(\mathrm{X}_{1}\right)$ dan perceived parental monitoring $\left(\mathrm{X}_{2}\right)$ terhadap perilaku berisiko $(\mathrm{Y})$.

\section{HASIL DAN PEMBAHASAN}

Tabel 1 menunjukkan hasil bahwa sebanyak 395 siswa di Bandung berpartisipasi dalam penelitian ini dengan persentase remaja perempuan $59,25 \%$ dan remaja laki-laki $40,75 \%$. Rata-rata responden yang terlibat ialah remaja berusia 14 tahun sejumlah 102 orang $(25,82 \%)$. Diketahui pula bahwa frekuensi siswa SMP yang terlibat sebanyak 223 orang $(56,46 \%)$, sedangkan siswa SMA sejumlah 172 orang $(43,54 \%)$. Mayoritas remaja tinggal bersama ayah dan ibu sebanyak 341 orang $(86,33 \%)$.

Tabel 1, Gambaran Umum Responden

\begin{tabular}{cccc}
\hline \multicolumn{2}{c}{ Data Responden } & Frekuensi & Persentase \\
\hline Jenis & Laki-laki & 161 & $40,75 \%$ \\
Kelamin & Perempuan & 234 & $59,25 \%$ \\
\hline & 13 & 71 & $17,97 \%$ \\
& 14 & 102 & $25,82 \%$ \\
Usia & 15 & 81 & $20,51 \%$ \\
& 16 & 71 & $17,97 \%$ \\
& 17 & 62 & $15,70 \%$ \\
& 18 & 8 & $2,03 \%$ \\
\hline Jenjang & SMP & 223 & $56,46 \%$ \\
Sekolah & SMA & 172 & $43,54 \%$ \\
\hline Tinggal & Ayah dan & 341 & $86,33 \%$ \\
Bersama & Ibu & &
\end{tabular}




\begin{tabular}{rcc}
\hline Data Responden & Frekuensi & Persentase \\
\hline Ayah & 10 & $2,53 \%$ \\
Ibu & 28 & $7,09 \%$ \\
Wali & 16 & $4,05 \%$ \\
\hline
\end{tabular}

Tabel 2. Deskripsi Personal Fable, Perceived Parental Monitoring dan Perilaku Berisiko

\begin{tabular}{cccc}
\hline Kategori & $\begin{array}{c}\text { Personal } \\
\text { Fable }\end{array}$ & $\begin{array}{c}\text { Perceived } \\
\text { Parental } \\
\text { Monitoring }\end{array}$ & $\begin{array}{c}\text { Perilaku } \\
\text { Berisiko }\end{array}$ \\
\hline Rendah & 211 & $211(53,42 \%)$ & 192 \\
& $(53,42 \%)$ & & $(48,61 \%)$ \\
\hline Tinggi & 184 & $184(46,58 \%)$ & 203 \\
& $(46,58 \%)$ & & $(51,39 \%)$ \\
\hline
\end{tabular}

Tabel 3, Uji Regresi Berganda Personal Fable dan Perceived Parental Monitoring terhadap Perilaku Berisiko

\begin{tabular}{cccccc}
\hline Model & B & Sig. & $\begin{array}{c}\text { Multipl } \\
\boldsymbol{e} \mathbf{R}\end{array}$ & $\begin{array}{c}\mathbf{R} \\
\text { Squar } \\
\boldsymbol{e}\end{array}$ & Sig. \\
\cline { 1 - 3 }$($ Constant $)$ & $\begin{array}{c}24,47 \\
1\end{array}$ & $\begin{array}{c}0,00 \\
0\end{array}$ & & & \\
\cline { 1 - 3 } $\begin{array}{c}\text { Personal } \\
\text { Fable }\end{array}$ & 0,369 & $\begin{array}{c}0,07 \\
9\end{array}$ & & & \\
\cline { 1 - 2 } $\begin{array}{c}\text { Perceived } \\
\text { Parental }\end{array}$ & $-0,646$ & 0,00 & & 0,193 & $* 00$ \\
$\begin{array}{c}\text { Monitorin } \\
g\end{array}$ & & 0 & & & \\
\hline
\end{tabular}

Hasil uji regresi berganda pada Tabel 3 menyimpulkan bahwa $\mathrm{H}_{0}$ tidak ditolak karena nilai $p$ value untuk variabel personal fable sebesar 0,079 $(>0,05)$ menandakan bahwa personal fable tidak berpengaruh terhadap perilaku berisiko, sedangkan untuk variabel perceived parental monitoring nilai $p$ value sebesar $0,000 \quad(<0,05)$ memberi arti bahwa terdapat pengaruh perceived parental monitoring terhadap perilaku berisiko.

Besaran pengaruh personal fable dan perceived parental monitoring terhadap perilaku berisiko dapat dilihat dari persamaan berikut:

$$
\mathrm{Y}=-24,471+0,369 \mathrm{X} 1+(-0,646) \mathrm{X} 2+\mathrm{e}
$$

Angka -24,471 di atas merupakan nilai konstanta perilaku berisiko $(\mathrm{Y})$ yang berarti bahwa jika tidak terdapat dua variabel independen, maka perilaku berisiko bernilai -24,471, Angka 0,369 menunjukkan nilai koefisien regresi yang berarti bahwa apabila personal fable (X1) naik satu satuan dan perceived parental monitoring (X2) dikendalikan, maka perilaku berisiko (Y) akan naik sebesar 0,369. Selanjutnya, angka -0,646 menunjukkan bahwa ketika personal fable (X1) dikendalikan dan perceived parental monitoring (X2) naik satu satuan, maka perilaku berisiko (Y) akan turun sebesar 0,646,

Hasil menunjukkan bahwa secara simultan tidak terdapat pengaruh personal fable dan perceived parental monitoring terhadap perilaku berisiko. Skor personal fable dalam penelitian ini berdasarkan Tabel
2 ialah rendah $(53,42 \%)$, sedangkan skor perilaku berisiko berdasarkan Tabel 2 pada penelitian ini tinggi $(51,39 \%)$. Pada penelitian lain (Landicho dkk., 2014), umumnya korelasi antara personal fable terhadap perilaku berisiko adalah korelasi positif yang mana apabila skor personal fable tinggi, maka skor perilaku berisiko akan tinggi juga.

Di samping itu, terdapat beberapa peneliti yang memang membantah teori personal fable yang dikembangkan oleh David Elkind. Menurut peneliti tersebut, remaja mampu merasa rentan terhadap dampak negatif dari perilaku berisiko tetapi tetap melakukan perilaku tersebut (Holland \& Klaczynski, 2009; Johnson, McCaul, \& Klein, 2002). Siegel (2004) pun turut membantah teori dari Elkind karena hasil penelitiannya menunjukkan bahwa ketika remaja memiliki keinginan atau tujuan, dalam mencapai hal tersebut remaja cenderung akan melakukan perilaku yang diketahui berisiko dan menerima dampak dari perilakunya. Semakin besar kebutuhan remaja untuk mencapai tujuannya, maka akan semakin besar kesediaan remaja untuk menanggung risiko di masa yang akan datang.

Sementara itu, perceived parental monitoring terhadap perilaku berisiko dalam penelitian ini berkorelasi secara negatif sehingga sejalan dengan temuan-temuan penelitian sebelumnya, yaitu perceived parental monitoring yang rendah berkorelasi dengan perilaku berisiko yang tinggi (DiClemente dkk., 2001; Springer, Sharma, De Guardado, Nava, \& Kelder, 2006; Strunin dkk., 2013). Perceived parental monitoring dianggap penting sebagai hal yang mampu melindungi remaja dari perilaku berisiko. Perceived parental monitoring yang tinggi dianggap mampu menurunkan perilaku remaja dari keterlibatannya dalam perilaku berisiko (Lac \& Crano, 2009). Remaja yang merasa diawasi dengan ketat oleh orang tuanya cenderung tidak akan melakukan perilaku yang berisiko (Mukminah, 2017).

Pengaruh perceived parental monitoring terhadap perilaku berisiko dapat dilihat dari dimensi yang memberikan pengaruh paling besar. Hal tersebut dicantumkan pada Tabel 4,

Tabel 4 Pengaruh Dimensi Perceived Parental Monitoring terhadap Perilaku Berisiko

\begin{tabular}{ccc}
\hline Model & B & Sig. \\
\hline (Constant) & $-8,162$ & 0,025 \\
\hline $\begin{array}{c}\text { Parental } \\
\text { Knowledge }\end{array}$ & $-0,095$ & 0,195 \\
\hline $\begin{array}{c}\text { Parental } \\
\text { Solicitation }\end{array}$ & 0,015 & 0,757 \\
\hline $\begin{array}{c}\text { Parental } \\
\text { Control }\end{array}$ & $-0,129$ & 0,001 \\
\hline $\begin{array}{c}\text { Youth } \\
\text { Disclosure }\end{array}$ & $-0,325$ & 0,000 \\
\hline
\end{tabular}

Tabel 4 menunjukkan bahwa dimensi youth disclosure merupakan dimensi yang paling berpengaruh terhadap perilaku berisiko dengan nilai 
sig. $0,000(<0,05)$ kemudian dilanjut oleh dimensi parental control dengan nilai sig. $0,001(<0,05)$. Wang dkk. (2013) menjelaskan bahwa dimensi youth disclosure secara signifikan dapat mengurangi perilaku berisiko. Van der Vorst, Engels, Meeus, \& Deković (2006) pun dalam penelitiannya melaporkan bahwa parental control yang ketat cenderung berkaitan dengan perilaku berisiko yang rendah pada remaja.

\section{SIMPULAN}

Berdasarkan hasil dan pembahasan, maka didapat kesimpulan bahwa tidak terdapat pengaruh personal fable dan perceived parental monitoring secara simultan terhadap perilaku berisiko pada remaja di Kota Bandung. Personal fable yang rendah dalam penelitian ini diketahui tidak berpengaruh terhadap perilaku berisiko, sedangkan perceived parental monitoring berpengaruh terhadap perilaku berisiko. Dimensi perceived parental monitoring yang memiliki pengaruh paling besar ialah dimensi youth disclosure.

\section{DAFTAR PUSTAKA}

Aminah, A. N. (2017, Mei 8), Republika.co.id. Kondisi Perokok dari Kalangan Siswa di Bandung Mengkhawatirkan. Diakses pada 13 Oktober 2018 dari:

https://www.republika.co.id/berita/nasional/daera h/17/05/08/opmxkn384-kondisi-perokok-darikalangan-siswa-di-bandung-mengkhawatirkan..

Anonim. (2013, Februari 13), Detik.com. Duh, Pelajar di Jabar Tertinggi Pengguna Narkoba, Diakses pada $20 \quad$ Februari 2019 dari: https://m.detik.com/news/berita-jawa-barat/d2173861/duh-pelajar-di-jabar-tertinggipengguna-narkoba.

Azizah, K. N. (2018, Oktober 9), Detik.com. Konsumsi Alkohol pada Remaja Usia Sekolah Meningkat. Didapat dari: https://m.detik.com/health/beritadetihealth/d-4248970/konsumsi-alkohol-padaremaja-usia-sekolah-meningkat.

Badan Kependudukan dan Keluarga Berencana Nasional. (2018). Survei Demografi dan Kesehatan Indonesia. Diakses pada 8 April 2019 dari http://sdki.bkkbn.go.id.

Creswell, J. W. (2012). Educational research: Planning, conducting, and evaluating quantitative and qualitative research. 4th Ed. Boston: Pearson.

DiClemente, R. J., Wingood, G. M., Crosby, R., Sionean, C., Cobb, B. K., Harrington, K., ... \& Oh, M. K. (2001). Parental monitoring: Association with adolescents' risk behaviors. Pediatrics, 107(6), 1363-1368,

Dittus, P. J., Michael, S. L., Becasen, J. S., Gloppen, K. M., McCarthy, K., \& Guilamo-Ramos, V. (2015). Parental monitoring and its associations with adolescent sexual risk behavior: A meta-analysis. Pediatrics, 136(6), e1587-e1599.
Hansen, E. B., \& Breivik, G. (2001). Sensation seeking as a predictor of positive and negative risk behaviour among adolescents. Personality and individual differences, 30(4), 627-640,

Holland, J. D., \& Klaczynski, P. A. (2009). Intuitive risk-taking during adolescence. The Prevention Researcher, 16(2), 8-12.

Johnson, R. J., McCaul, K. D., \& Klein, W. M. (2002). Risk involvement and risk perception among adolescents and young adults. Journal of behavioral medicine, 25(1), 67-82.

Lac, A., \& Crano, W. D. (2009). Monitoring matters: Meta-analytic review reveals the reliable linkage of parental monitoring with adolescent marijuana use. Perspectives on Psychological Science, 4(6), 578-586,

Landicho, D. L. C., Cabanig, M. C. A., Cortes, M. S. F., \& Villamor, B. J. B. (2014). Egocentrism and risk-taking among adolescents. Asia Pacific Journal of Multidisciplinary Research| Vol, 2(3).

Leather, N. C. (2009). Risk-taking behaviour in adolescence: a literature review. Journal of Child Health Care, 13(3), 295-304,

Laird, R. D., Marrero, M. D., \& Sentse, M. (2010). Revisiting parental monitoring: Evidence that parental solicitation can be effective when needed most. Journal of Youth and Adolescence, 39(12), 1431-1441,

Lapsley, D. K., FitzGerald, D. P., Rice, K. G., \& Jackson, S. (1989). Separation-individuation and the" new look" at the imaginary audience and personal fable: A test of an integrative model. Journal of Adolescent Research, 4(4), 483-505.

Mukminah, M. (2017). Hubungan monitoring parental dan kebiasaan peer-group dengan perilaku merokok remaja SLTP di Kota Mataram. Jurnal Biosains, 3(3), 131-136,

Ritcher, M. 2010, Risk Behavior in Adolescence, Patterns, Determinants, and Consequences. Germany: Springer Fachmedien.

Saudi, A. N. A., Hartini, N., Bahar, B. (2018). Teenagers' motorcycle gang community aggression from the personal fable and risk-taking behavior perspective. Psychology Research and Behavior Management, 11, 305-309.

Siegel, J. (2004). The imaginary audience, the personal fable, and a rival hypothesis: An alternative explanation for behavior typical of adolescence (Ph. D dissertation.) Arizona: The University of Arizona.

Springer, A. E., Sharma, S., De Guardado, A. M., Nava, F. V., \& Kelder, S. H. (2006). Perceived parental monitoring and health risk behavior among public secondary school students in El Salvador. The Scientific World Journal, 6, 1810-1814,

Statistik Pemuda Indonesia. (2014). Hasil Survei Sosial Ekonomi Nasional. Jakarta: Badan Pusat Statistik.

Stattin, H., \& Kerr, M. (2000). Parental monitoring: A reinterpretation. Child development, 71(4), 10721085.

Stattin, H., Kerr, M., Tilton-Weaver, L. (2010). Parental monitoring: a critical examination oof 
the research. Contemporary Issues in Parental Monitoring, 1, 3-38,

Strunin, L., Martínez, A. D., Díaz-Martínez, L. R., Heeren, T., Kuranz, S., Winter, M., ... \& SolísTorres, C. (2013). Parental monitoring and alcohol use among Mexican students. Addictive Behaviors, 38(10), 2601-2606,

Sulistiyowati, N. \& Senewe F. P. (2010). Pola pencarian pengobatan dan perilaku berisiko remaja di Indonesia (Analisis Lanjut Data Riskesdas 2007). Jurnal Ekologi Kesehatan, 9(4), 1347-1356,

Suwarni, L., Ismail, D., Prabandari, Y. S., \& Adiyanti, M. G. (2015). Perceived parental monitoring on adolescence premarital sexual behavior in Pontianak City, Indonesia. International Journal of Public Health Science (IJPHS), 4(3), 211-219.

Van der Vorst, H., Engels, R. C., Meeus, W., \& Deković, M. (2006). Parental attachment, parental control, and early development of alcohol use: A longitudinal study. Psychology of addictive behaviors, 20(2), 107.

Villarreal, D. L., \& Nelson, J. A. (2018). Parental monitoring and adolescent risk behaviors: the moderating role of adolescent internalizing symptoms and gender. Journal of Child and Family Studies, 27(11), 3627-3637.

Walsh, S. D., Harel-Fisch, Y., \& Fogel-Grinvald, H. (2010). Parents, teachers and peer relations as predictors of risk behaviors and mental well-being among immigrant and Israeli born adolescents. Social Science \& Medicine, 70(7), 976-984.

Wang, B., Stanton, B., Li, X., Cottrell, L., Deveaux, L., \& Kaljee, L. (2013). The influence of parental monitoring and parent-adolescent communication on Bahamian adolescent risk involvement: A three-year longitudinal examination. Social Science \& Medicine, 97, 161169.

Ungsianik, T.\& Yuliati T. (2017). Pola Asuh Orang tua Berhubungan dengan Perilaku Seksual Berisiko pada Remaja Binaan Rumah Singgah. Jurnal Keperawatan Indonesia, 20(3), 185-194. 